\title{
Sequence determination of a satellite RNA isolated from Aspergillus foetidus
}

Unnati A. Shah ${ }^{1,2}$, loly Kotta-Loizou ${ }^{1}$ and Robert H.A. Coutts ${ }^{1,2}$

${ }^{1}$ Department of Life Sciences, Faculty of Natural Sciences, Imperial College London, Sir Alexander Fleming Building, Imperial College Road, London SW7 2AZ, UK

${ }^{2}$ School of Life and Medical Sciences, University of Hertfordshire, Hatfield, AL10 9AB, UK

e-mail: i.kotta-loizou13@imperial.ac.uk

\begin{abstract}
Aspergillus foetidus virus (AfV) contains at least two distinct particle types designated as AfV-fast (F) and AfV-slow (S). AfV-S contains AfV-S1, a victorivirus, AfV-S2, an unclassified satellite RNA, and AfVS3, a previously uncharacterized dsRNA element. Here we describe the complete sequence of AfV-S3, which is a short non-coding RNA with no known homologs. AfV-S3 is predicted to form extended secondary structure, shares a $5^{\prime}$-terminus with AfV-S2 and is a satellite RNA possibly dependent on both AfV-S1 and AfV-S2. This work concludes the sequencing of the A. foetidus virome.
\end{abstract}

\section{Introduction}

Double-stranded (ds) RNA mycoviruses have been described in yeasts, mushrooms and filamentous fungi; they are classified into six families based on their virion structure and genome composition, but some still remain unassigned to a genus or family. Satellite RNAs, which rely on their helper virus for maintenance, are commonly associated with fungal viruses. The most prominent and well-studied example is the killer-toxin-encoding dsRNA that accompany the Saccharomyces cerevisiae L-A totivirus [17], while a number of satellite RNAs dependent on various members of the Partitiviridae family have also been noted $[6,10,14]$.

In the genus Aspergillus, the presence of dsRNA mycoviruses from the families Totiviridae, Partitiviridae and Chrysoviridae has been reported, and mixed infections are common $[4,8,16]$. More specifically, Aspergillus foetidus isolate IMI 41871 has been found to harbour at least two different types of isometric virus particles, designated as A. foetidus virus-fast (AfV-F) and -slow (AfV-S), based on their relative electrophoretic mobility $[3,15]$. The quadripartite polyadenylated dsRNA virus present in AfV-F virions is similar to Alternaria alternata virus 1 , both members of a putative novel mycovirus family [12], while AfV-S virions contain AfV-S1, a member of the genus Victorivirus in the family Totiviridae [11], AfV-S2, a putative satellite RNA similar to an unclassified RNA from the fungus 
Rosellinia necatrix [13] and AfV-S3, an uncharacterized small dsRNA element, approximately $0.4 \mathrm{kbp}$ in length. In this paper, we report the complete sequence of the AfV-S3 dsRNA element.

\section{Provenance of the virus material}

Aspergillus foetidus (Thom and Raper) isolate IMI 41871 (CBS 618-78), originating from Carl A. Neuberg in Berlin, Germany, and probably isolated in the 1940s, was grown in a 60-litre fermenter.

Purification of virus particles was performed as described previously [2] and two different types of virus particles designated AfV-F and AfV-S, according to their electrophoretic mobilities, were separated by rate zonal sucrose density gradient centrifugation [5] and stored in $50 \%$ glycerol at $4^{\circ} \mathrm{C}$. The AfV-S dsRNA elements were extracted using phenol/Sevag treatment and separated by electrophoresis on a $1 \%(\mathrm{w} / \mathrm{v})$ agarose gel containing Tris-acetate-EDTA (TAE) buffer and $500 \mathrm{ng} / \mathrm{ml}$ ethidium bromide (Fig. 1a). The smallest segment was extracted from the gel using the MinElute Gel Extraction Kit (Qiagen) and was used as a template in a modified protocol of RNA ligase-mediated rapid amplification of cDNA ends [7]. Due to the small size of the dsRNA element (ca. $0.4 \mathrm{kbp}$ ), no sequence-specific primers were required and the whole element was amplified, cloned using the pGEM-T Easy vector system (Promega) and introduced into competent Escherichia coli XL10-Gold cells (Agilent). Four different clones of the element were sequenced. One of them was used as a template for the production of a digoxygenin (DIG)-labelled probe with the DIG Northern Starter Kit (Roche) and the origin of the clones was confirmed by northern blotting, hybridization and chemiluminescent detection according to the manufacturer's instructions (Fig. 1b).

\section{Sequence properties}

The sequence of the AfV-S3 dsRNA element has been deposited in the GenBank/EMBL/DDBJ databases with accession number LN614706. AfV-S3 consists of a single dsRNA of $439 \mathrm{bp}$, which has a GC content of $53 \%$. Sequence similarity searches of the GenBank and EMBL databases using the BLAST program [1], revealed no statistically significant homology between AfV-S3 and other known sequences, including the other AfV-S components and AfV-F. Additionally, AfV-S3 contains no open reading frames (ORFs) of significant length in either strand; both strands were found to contain short ORFs potentially encoding polypeptides less than $9 \mathrm{kDa}$ in mass that lack significant sequence similarity with proteins in the databases. Therefore, it is unlikely that these polypeptides are actually produced.

Secondary structure analysis of the AfV-S3 dsRNA using the mfold server [18] indicated that ca. 54\% of the ribonucleotides are involved in the formation of secondary structures and predicted the presence of stem-loop structures (Fig. 1c), which are common in mycoviruses and considered to be 
implicated in RdRp recognition and RNA replication [9]. Interestingly, the first seven nucleotides of the AfV-S3 5'-terminus (5'-GGGATTT-3') are identical to those of AfV-S2, suggesting that AfV-S3 may be using the RNA-dependent RNA polymerase encoded by AfV-S2 to replicate. AfV-S1, AfV-S2 and AfV-S3 dsRNA elements are all derived from the AfV-S virus particles, which consist of a capsid protein most probably produced by AfV-S1, a victorivirus and the only AfV-S component to encode a structural protein. Therefore, AfV-S3 may be a satellite RNA dependent on two different viruses; AfV-S2 for its replication and AfV-S1 for its encapsidation.

\section{Acknowledgements}

We would like to thank Professor Kenneth Buck for supplying purified Aspergillus foetidus virus.

\section{References}

1. Altschul SF, Madden TL, Schäffer AA, Zhang J, Zhang Z, Miller W, Lipman DJ (1997) Gapped BLAST and PSI-BLAST: a new generation of protein database search programs. Nucleic Acids Res 25:3389-3402

2. Banks GT, Buck KW, Chain EB, Darbyshire JE, Himmelweit F (1969) Virus-like particles in penicillin producing strains of Penicillium chrysogenum. Nature 223:89-90

3. Banks GT, Buck KW, Chain EB, Darbyshire JE, Himmelweit F, Ratti G, Sharpe TJ, Planterose DN (1970) Antiviral activity of double stranded RNA from a virus isolated from Aspergillus foetidus. Nature 227:505-507

4. Bhatti MF, Jamal A, Bignell EM, Petrou MA, Coutts RHA (2012) Incidence of dsRNA mycoviruses in a collection of Aspergillus fumigatus isolates. Mycopathologia 174:323-326

5. Buck KW, Girvan RF (1977) Comparison of the biophysical and biochemical properties of Penicillium cyaneo-fulvum virus and Penicillium chrysogenum virus. J Gen Virol 34:145-154

6. Compel P, Papp I, Bibo M, Fekete C, Hornok, L. (1999) Genetic relationships and genome organization of double-stranded RNA elements of Fusarium poae. Virus Genes 18:49-56

7. Coutts RHA, Livieratos IC (2003) A rapid method for sequencing the $5^{\prime}$ - and $3^{\prime}$-termini of dsRNA viral templates using RLM-RACE. J Phytopath 151:525-527

8. Jamal A, Bignell EM, Coutts RHA (2010) Complete nucleotide sequences of four dsRNAs associated with a new chrysovirus infecting Aspergillus fumigatus. Virus Res 153:64-70

9. Ghabrial SA, Suzuki N (2009) Viruses of plant pathogenic fungi. Ann Rev Phytopath 47:353-384

10. Kim JW, Choi EY, Lee JI (2005) Genome organization and expression of the Penicillium stoloniferum virus F. Virus Genes 31:175-183

11. Kozlakidis Z, Herrero N, Coutts RHA (2013) The complete nucleotide sequence of a totivirus from Aspergillus foetidus. Arch Virol 158:263-266 
12. Kozlakidis Z, Herrero N, Ozkan S, Kanhayuwa L, Jamal A, Bhatti MF, Coutts RHA (2013) Sequence determination of a quadripartite dsRNA virus isolated from Aspergillus foetidus. Arch Virol $158: 267-272$

13. Kozlakidis Z, Herrero N, Ozkan S, Bhatti MF, Coutts RHA (2013) A novel dsRNA element isolated from the Aspergillus foetidus mycovirus complex. Arch Virol 158:2625-2628

14. Oh CS, Hillman BI (1995) Genome organization of a partitivirus from the filamentous ascomycete Atkinsonella hypoxylon. J Gen Virol 76:1461-1470

15. Ratti G, Buck KW (1972) Virus particles in Aspergillus foetidus: a multicomponent system. J Gen Virol 14:165-175

16. van Diepeningen AD, Varga J, Hoekstra RF, Debets AJM (2008) In: Varga J, Samson, RA (eds) Mycoviruses in the Aspergilli, Aspergillus in the genomic era, Wageningen Academic Publishers, Wageningen, pp 133-176

17. Wickner RB, Fujimura T, Esteban R (2013) Viruses and prions of Saccharomyces cerevisiae. Adv Virus Res 86:1-36

18. Zuker M (2003) Mfold web server for nucleic acid folding and hybridization prediction. Nucleic Acids Res 31:3406-3415 
(a)

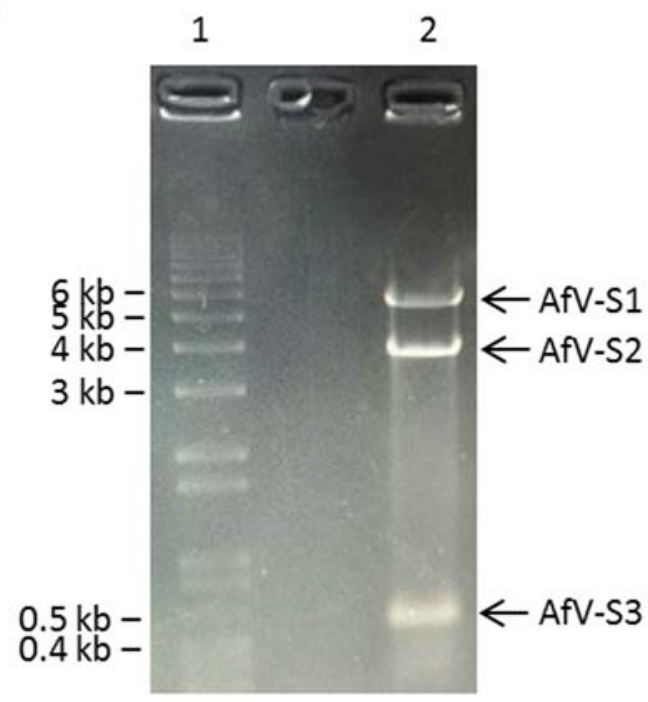

(b)

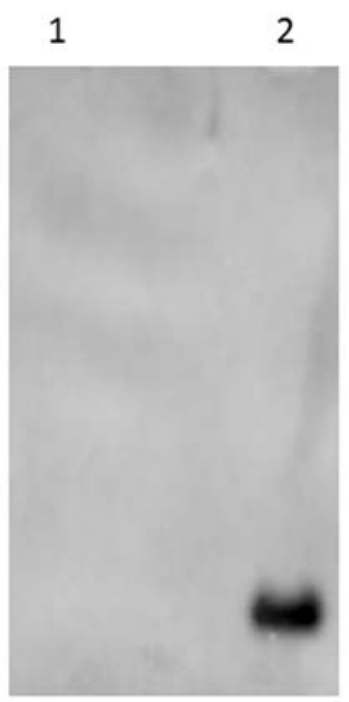

(c)

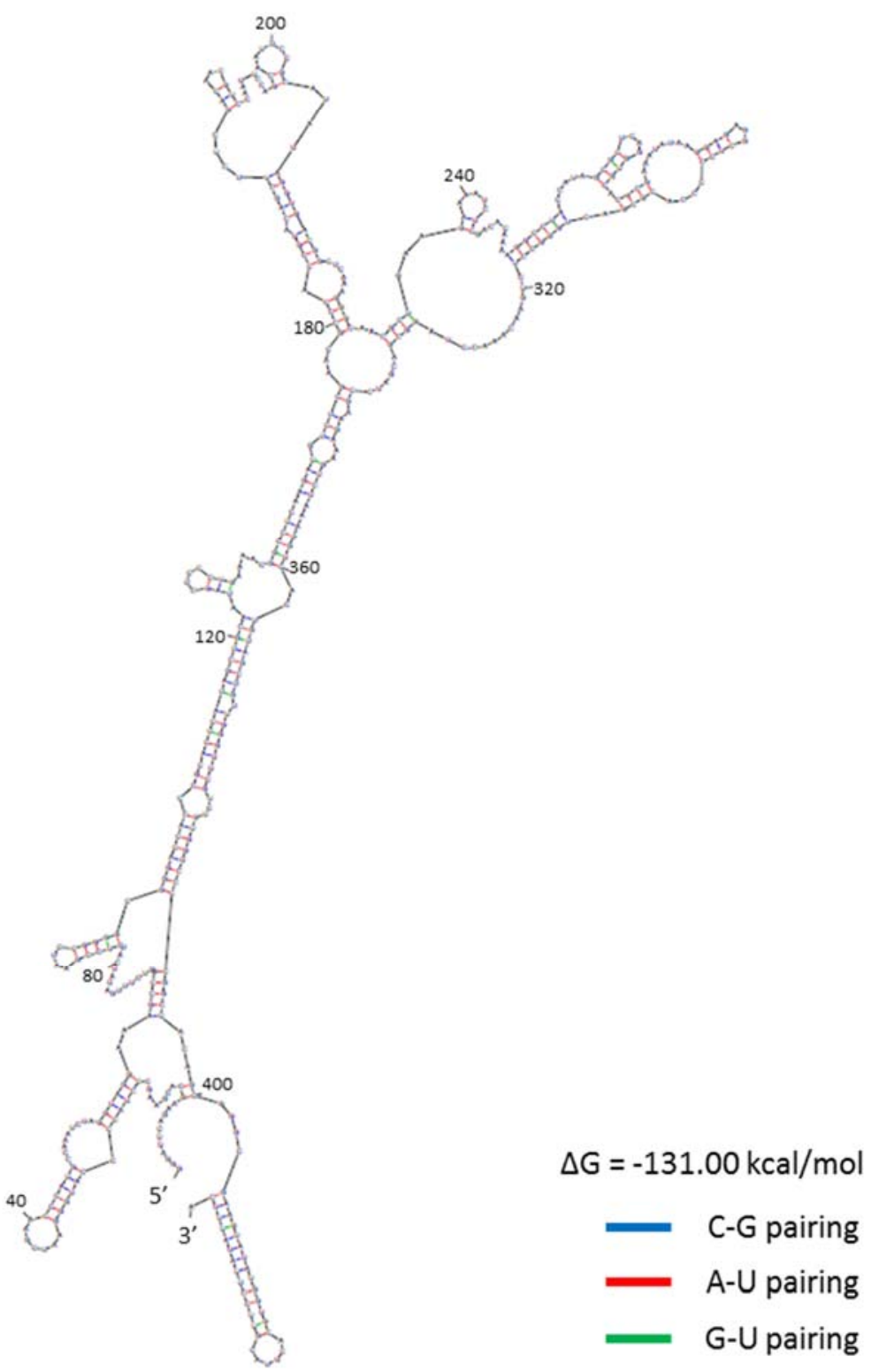


Fig. 1 (a) Agarose electrophoresis of AfV-S viruses from A. foetidus isolate IMI 41871 (lane 2). AfV-S1, AfV-S2 and AfV-S3 are indicated by arrows. Lane 1 contains the $1 \mathrm{~kb}$ Plus DNA Ladder (Invitrogen), the sizes of with is shown to the left of the gel. (b) Northern blot hybridization of AfV-S3 using a DIGlabelled probe derived from its cloned sequence. (c) Schematic representation of the minimum free energy structure of the AfV-S3 sequence, as predicted by mfold. 